\title{
Safety creatinine clearance level for platinum chemotherapy in lung cancer patients
}

\author{
GEN OHARA $^{1,2}$, KUNIHIKO MIYAZAKI ${ }^{2}$, KOICHI KURISHIMA ${ }^{2}$, KATSUNORI KAGOHASHI ${ }^{1}$, \\ HIROICHI ISHIKAWA ${ }^{3}$, HIROAKI SATOH ${ }^{1}$ and NOBUYUKI HIZAWA ${ }^{2}$
}

\author{
${ }^{1}$ Division of Respiratory Medicine, Mito Medical Center; ${ }^{2}$ Division of Respiratory Medicine, Institute of Clinical Medicine, \\ University of Tsukuba, Mito, Ibaraki; ${ }^{3}$ Division of Respiratory Medicine, Tsukuba Medical Center, Tsubuka, Ibaraki, Japan
}

Received July 8, 2011; Accepted October 11, 2011

DOI: $10.3892 / \mathrm{ol} .2011 .486$

\begin{abstract}
The present study was carried out to evaluate whether measured-creatinine clearance (measured- $\mathrm{CrCl}$ ) and Cockcroft and Gault- $\mathrm{CrCl}(\mathrm{CG}-\mathrm{CrCl})$ are capable of appropriately detecting a decline in renal function in lung cancer patients, including elderly patients, and to clarify a $\mathrm{CrCl}$ level with which to discriminate between patients with or without renal impairment. The measured- $\mathrm{CrCl}$ prior and subsequent to platinum-based chemotherapy of lung cancer patients was retrospectively analyzed. Measured- $\mathrm{CrCl}$ and $\mathrm{CG}-\mathrm{CrCl}$ were evaluated prior and subsequent to platinum-based chemotherapy for lung cancer. Measured-CrCl and $\mathrm{CG}-\mathrm{CrCl}$ in 59 lung cancer patients including 25 patients aged $\geq 65$ years were retrospectively analyzed. In patients treated with carboplatin-based chemotherapy, measured- $\mathrm{CrCl}$ was indicative of a decline in renal function, whereas $\mathrm{CG}-\mathrm{CrCl}$ was not. The optimal measured-CrCl level was $<60 \mathrm{ml} / \mathrm{min}$ post-pretreatment and $>90 \mathrm{ml} / \mathrm{min}$ at pre-treatment. In cases with pre-treatment measured- $\mathrm{CrCl}$ levels of $>90 \mathrm{ml} / \mathrm{min}$, favorable renal function is necessary in order to carry out platinum-based chemotherapy in lung cancer patients, including the elderly.
\end{abstract}

\section{Introduction}

Lung cancer in the elderly is an increasingly common problem. Elderly patients have more co-morbid diseases and tend to tolerate toxic medical treatments more poorly than younger patients (1). Recently, however, clinical trials of platinum-based chemotherapy for selected elderly lung cancer patients with favorable conditions have been conducted, and have attracted attention to the utility of such therapy for the elderly $(2,3)$. Cisplatin is highly effective and has a significant role in the

Correspondence to: Dr Hiroaki Satoh, Division of Respiratory Medicine, Mito Medical Center, University of Tsukuba, Miya-machi 3-2-7, Mito, Ibaraki 310-0015, Japan

E-mail: hirosato@md.tsukuba.ac.jp

Key words: renal function, creatinine clearance, lung cancer, elderly treatment of lung cancer, but chronic ototoxicity, neurotoxicity and particularly nephrotoxicity have encouraged the development of several less toxic platinum analogues, principally carboplatin (4). Carboplatin nephrotoxicity appears to be less frequent and severe than cisplatin nephrotoxicity (4). In 1994, Thyss et al reported Cockcroft and Gault-creatinine clearance $(\mathrm{CG}-\mathrm{CrCl})$ levels in 35 patients older than 80 years who received cisplatin-based chemotherapy (5); however, there has been no additional published information regarding $\mathrm{CrCl}$ levels at which it is safe to perform platinum-based chemotherapy for lung cancer patients, including elderly patients.

The first aim of this retrospective study was to clarify whether measured-CrCl and $\mathrm{CG}-\mathrm{CrCl}$ were capable of appropriately detecting a decline in renal function. An additional aim was to clarify a measured- $\mathrm{CrCl}$ level with which to discriminate between lung cancer patients, including elderly ones, with or without renal impairment.

\section{Patients and methods}

Patients. A total of 292 patients with newly diagnosed primary lung cancer who were admitted to the Division of Respiratory Medicine, Tsukuba Medical Center Hospital between 2007 and 2009, were retrospectively analyzed. In this study, 59 of 292 consecutive lung cancer patients whose creatinine clearance was measured over a period of $24 \mathrm{~h}$ prior and subsequent to platinum-based chemotherapy for lung cancer, were included. For each patient, the diagnosis of lung cancer was confirmed with pathological and/or cytological specimens. Pathological and/or cytological diagnosis was defined by the WHO classification and patients were staged according to the UICC TNM system (6). Age, height, actual body weight and gender were recorded at the initial visit.

$\mathrm{CrCl}$. Urinary and serum creatinine, and BUN were measured using the enzymatic method. Prior to commencement of the lung cancer treatment, measured-CrCl was calculated 3 times in all patients and averaged. Post-chemotherapeutic measured- $\mathrm{CrCl}$ was evaluated 3 weeks after the completion of the therapy. For each patient, the $\mathrm{CrCl}$ was also estimated using the Cockcroft and Gault (CG) formula as follows: BSA $=0.007184 \mathrm{x} \mathrm{Ht}^{0.725} \mathrm{x} \mathrm{Wt}^{0.425}$; measured-CrCl $=(1.73 / \mathrm{BSA}) \mathrm{x}$ $(\mathrm{UCr} \times U v o l) /(24 \times 60 \times \mathrm{SCr}) ; \mathrm{CG}-\mathrm{CrCl}=(1.73 / \mathrm{BSA}) \times[(140-\mathrm{A}) /$ 
$(\mathrm{SCr}+0.2)] \times(\mathrm{Wt} / 72) \times 0.85$ [in the case of a female patient (7)], where BSA indicates body surface area $\left(\mathrm{m}^{2}\right)$; Ht, height $(\mathrm{cm})$; $\mathrm{Wt}$, body weight $(\mathrm{kg})$; $\mathrm{UCr}$, urine creatinine concentration (mg/dl) (using the enzymatic method); Uvol, 24-h urine volume (ml/day); $\mathrm{SCr}$, serum creatinine concentration $(\mathrm{mg} / \mathrm{dl})$ (using the enzymatic method); and A, age (years). We added 0.2 to an SCr value measured using an enzymatic peroxidase-antiperoxidase method in order to render it equivalent to the $\mathrm{SCr}$ value measured using the Jaffē method (8).

Statistical methods. Measured-CrCl exacerbation after platinum-based chemotherapy was evaluated as [(pre-treatment measured-CrCl - post-treatment measured-CrCl)/pre-treatment measured- $\mathrm{CrCl}$, expressed as a percentage. According to previous reports (9-11), we defined a $\mathrm{CrCl}$ level of $<60 \mathrm{ml} / \mathrm{min}$ as exacerbation.

Statistical significance between the 2 groups was determined using the Mann-Whitney U test and Chi-square test. Statistical significance between paired baseline and $\mathrm{CrCl}$ levels was evaluated by the Wilcoxon signed rank test. To determine whether age was a risk factor for decline of $\mathrm{CrCl}$ in platinum-based chemotherapy, a multivariate logistic regression analysis was performed. All statistical analyses were performed using SPSS 10.1 for Windows (SPSS, Chicago, IL, USA), and a probability value of $<0.05$ was considered significant.

\section{Results}

Characteristics of patients. The clinicopathological characteristics of the lung cancer patients are shown in Table I. Of the 59 patients, $74.6 \%(\mathrm{n}=44)$ were men. The median age was 62 years (range, $41-81$ years). There were 25 patients aged $\geq 65$ years. The lung cancers comprised 35 non-small cell carcinomas and 24 small cell carcinomas. In total, 4 patients had stage IA-IIIA, 19 patients had stage IIIB, and 36 patients had stage IV disease.

In total, 31 and 28 patients had cisplatin- and carboplatin-based chemotherapy, respectively. Their median age was 59 and 66 years, respectively. The median number of cisplatinand carboplatin-based chemotherapy courses was 2 (range, 1-4) and 3 (range, 1-4) per patient, respectively.

Cisplatin-based chemotherapy. In the 31 patients treated with cisplatin-based chemotherapy, post-chemotherapeutic measured- $\mathrm{CrCl}$ was lower than pre-chemotherapeutic measured- $\mathrm{CrCl}(\mathrm{P}=0.001$, Wilcoxon signed rank test) (Fig. 1). In $\mathrm{CG}-\mathrm{CrCl}$, a statistically significant difference was also observed $(\mathrm{P}=0.001)$.

In 9 patients aged $\geq 65$ years, no statistical decline was observed in measured-CrCl and CG- $\mathrm{CrCl}(\mathrm{P}=0.005$, and 0.065 , respectively). In 22 patients aged $<65$ years, post-chemotherapeutic measured-CrCl was lower than pre-chemotherapeutic measured- $\mathrm{CrCl}(\mathrm{P}=0.001)$. In $\mathrm{CG}-\mathrm{CrCl}$, this decline was also significant $(\mathrm{P}=0.001)$.

Carboplatin-based chemotherapy. In 28 patients treated with carboplatin-based chemotherapy, post-chemotherapeutic measured- $\mathrm{CrCl}$ was lower than pre-chemotherapeutic measured$\mathrm{CrCl}(\mathrm{P}=0.001)$ (Fig. 2). In $\mathrm{CG}-\mathrm{CrCl}$, however, this decline was not observed $(\mathrm{P}=0.065)$.
Table I. Characteristics of 59 patients with lung cancer.

\begin{tabular}{lc}
\hline Age (years) & Median, 62; range, 41-81 \\
Gender & $44(74.6 \%)$ \\
Male & $15(25.4 \%)$ \\
Female & \\
Histology & $29(49.2 \%)$ \\
Adenocarcinoma & $24(40.7 \%)$ \\
Small cell carcinoma & $6(10.1 \%)$ \\
Squamous cell carcinoma & \\
Clinical stage & $4(6.8 \%)$ \\
IA-IIIA & $19(32.2 \%)$ \\
IIIB & $36(61.0 \%)$ \\
IV & \\
Chemotherapy & $31(52.5 \%)$ \\
Cisplatin-based & $28(47.5 \%)$ \\
Carboplatin-based & \\
Number of courses \\
of chemotherapy \\
1-3 \\
4-6
\end{tabular}

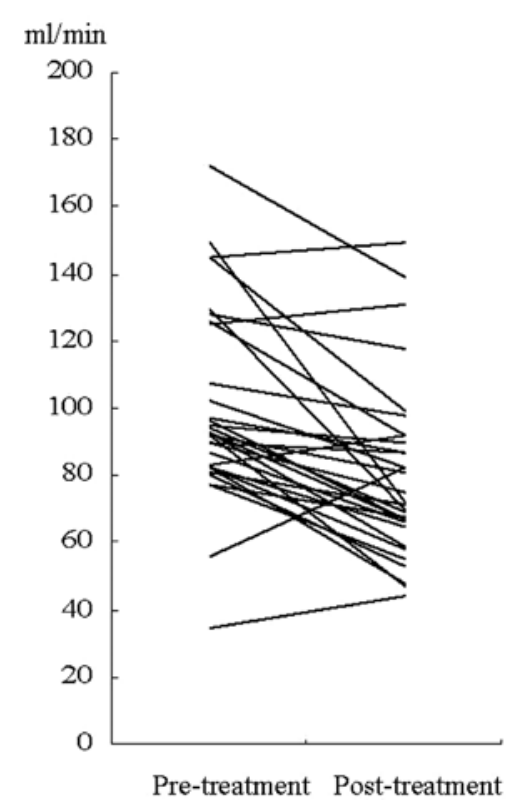

Figure 1. Changes in measured-CrCl prior and subsequent to cisplatin-based chemotherapy in 31 lung cancer patients.

In 16 patients aged $\geq 65$ years, the post-chemotherapeutic measured- $\mathrm{CrCl}$ level was lower than the pre-chemotherapeutic measured- $\mathrm{CrCl}$ level $(\mathrm{P}=0.009)$. In $\mathrm{CG}-\mathrm{CrCl}$, however, no statistically significant difference was observed between preand post-chemotherapy $(\mathrm{P}=0.278)$. In 12 patients aged $<65$ years, the post-chemotherapeutic measured-CrCl level was lower than the pre-chemotherapeutic measured- $\mathrm{CrCl}$ level $(\mathrm{P}=0.003)$. In $\mathrm{CG}-\mathrm{CrCl}$, however, no statistically significant difference was observed between pre- and post-chemotherapy $(\mathrm{P}=0.117)$. 


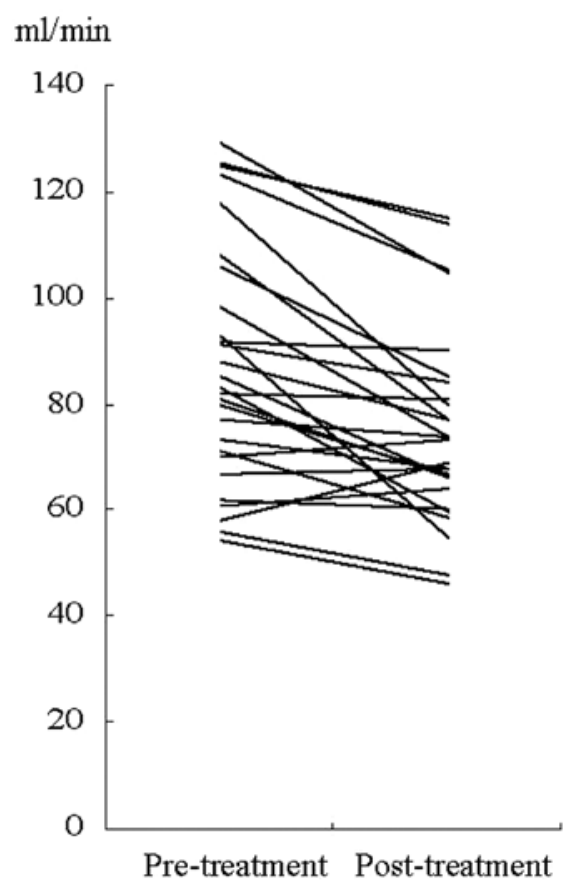

Figure 2. Changes in measured-CrCl prior and subsequent to carboplatinbased chemotherapy in 28 lung cancer patients.

Table II. Optimal pre-treatment cut-off level of measured-CrCl $(\mathrm{ml} / \mathrm{min})$ in 59 patients with lung cancer.

\begin{tabular}{|c|c|c|c|}
\hline \multirow{2}{*}{$\begin{array}{l}\text { Pre-treatment } \\
\text { measured-Cr-Cl } \\
(\mathrm{ml} / \mathrm{min})\end{array}$} & \multicolumn{3}{|c|}{$\begin{array}{c}\text { Post-treatment } \\
\text { measured-Cr-Cl levels (ml/min) }\end{array}$} \\
\hline & $<60(\mathrm{ml} / \mathrm{min})$ & $>60(\mathrm{ml} / \mathrm{min})$ & P-value \\
\hline$>70$ & 9 & 41 & \\
\hline$<70$ & 4 & 5 & 0.0969 \\
\hline$>80$ & 7 & 37 & \\
\hline$<80$ & 6 & 9 & 0.0733 \\
\hline$>90$ & 3 & 28 & \\
\hline$<90$ & 10 & 18 & 0.0262 \\
\hline$>100$ & 0 & 17 & \\
\hline$<100$ & 13 & 29 & 0.0121 \\
\hline
\end{tabular}

Optimal pre-treatment cut-off measured-CrCl level. To obtain the optimal pre-treatment cut-off measured- $\mathrm{CrCl}$ level with which to discriminate between patients becoming post-treatment $\mathrm{CrCl}$ level $<60 \mathrm{ml} / \mathrm{min}$ as exacerbation, patients were divided into groups based on whether their post-treatment measured- $\mathrm{CrCl}$ levels were $<$ or $>60 \mathrm{ml} / \mathrm{min}$ and subdivided into groups with pre-treatment measured-CrCl levels of 70,80 , 90 and $100 \mathrm{ml} / \mathrm{min}$. As shown in Table II, a statistically significant difference was observed when patients were divided into groups at pre-treatment measured- $\mathrm{CrCl}$ levels of 90 and $100 \mathrm{ml} / \mathrm{min}$. These comprised 31 of 59 patients including 8 of 25 elderly patients with $\geq 90 \mathrm{ml} / \mathrm{min}$ levels of pre-treatment measured- $\mathrm{CrCl}$. Among these, only 2 younger and 1 patient aged $\geq 65$ years, who were treated with cisplatin-based chemotherapy, developed a post-treatment measured-CrCl level of $<60 \mathrm{ml} / \mathrm{min}$. However, none of the elderly patients treated with carboplatin-based chemotherapy, developed a $\mathrm{CrCl}$ level of $<60 \mathrm{ml} / \mathrm{min}$. When the cut-off level was set at $100 \mathrm{ml} / \mathrm{min}$, no patients exhibited a post-treatment measured $\mathrm{CrCl}$ of $<60 \mathrm{ml} / \mathrm{min}$, although only 17 of 59 patients ( 3 of 25 patients aged $\geq 65$ years) exhibited such favorable pre-treatment measured-CrCl levels.

\section{Discussion}

As an early detection method and curative therapy have yet to be established, lung cancer patients have a high possibility of receiving chemotherapy at the time of the first presentation or at recurrence. Since the discovery of the anti-neoplastic effects of platinum-based compounds, cisplatin and, later, carboplatin have developed into commonly used anticancer agents (4). Although the proportion of elderly patients aged $\geq 80$ years continues to increase, intensive chemotherapy yields a clinical benefit to elderly lung cancer patients. Recently, Quoix reported that treatment with platinum-based doublet chemotherapy resulted in better survival for elderly patients with non-small cell lung cancer than standard single-agent therapy (12). However, there has been no additional published information regarding the $\mathrm{CrCl}$ level at which chemotherapy can be safely administered to lung cancer patients, including elderly patients. It is well known that renal function decreases with aging and that morphological changes, e.g., decrease of kidney weight, appearance of sclerotic glomeruli (13) and intimal proliferation in the renal artery are causes of renal dysfunction (14). An assessment of renal function is desirable when determining the dosage of drugs with a narrow therapeutic index and those that are renally excreted, in particular cytotoxic chemotherapeutic agents. Serum creatinine concentration remains the most widely used index of renal function in clinical practice (15). In the elderly, however, serum creatinine is not always beneficial as a marker of renal function since creatinine production is low due to decreased muscle mass $(16,17)$. The glomerular filtration rate (GFR) is generally used as an index of renal function and can be accurately measured through the renal clearance of either cold (inulin, iohexol) or radiolabeled (51Cr-EDTA, 99mTc-DTPA) exogenous filtration markers (18-21). Nonetheless, these methods are seldom available in clinical practice because they are invasive and expensive and require the use of radioelements for isotopic clearance determination. Instead of these methods, indirect methods are used for bedside renal function estimates, all of which are based on $\mathrm{CrCl}$.

In the present study we showed two significant points. Firstly, our results clearly revealed a decline in renal function even in the case of carboplatin-based chemotherapy for the elderly and younger patients, although it is well known that renal function should be closely observed in the case of cisplatin-based chemotherapy. Not only for the elderly but also for the younger patients, therefore, evaluation of renal function is essential in order to avoid excessive dosage of cisplatin or carboplatin. In addition, we should note that this decline of renal function may not be detected when the CG formula is used. In selected elderly patients, it may be possible to conduct 
clinical trials of platinum-based chemotherapy. Secondly, we found that patients with favorable renal condition whose pre-treatment measured-CrCl was $>90 \mathrm{ml} / \mathrm{min}$ were capable of undergoing cisplatin-based chemotherapy even though they were aged $\geq 65$ years. However, as 1 elderly patent with a pre-treatment measured- $\mathrm{CrCl}$ level of $92 \mathrm{ml} / \mathrm{min}$ fell to $47 \mathrm{ml} / \mathrm{min}$, it is crucial that cisplatin-based chemotherapy is administered with care even in the case of patients with favorable renal condition, particularly the elderly.

Despite the current study's novel findings, it had several limitations. Firstly, GFR was not determined using the isotopic reference method. Such methods are difficult to use in elderly patients with lung cancer, as they are invasive and seldom readily available in oncological practice. The use of the isotopic method in the elderly patients in our study would have induced a marked selection bias. Secondly, this was a retrospective study and our findings were obtained from a limited number of patients treated with cisplatin- and carboplatin-based chemotherapy. It may be possible to conduct clinical trials of platinum-based chemotherapy for selected elderly patients with favorable conditions. Nevertheless, our results indicate that it is of note to report the management in clinical practice of unselected groups of elderly lung cancer patients.

In conclusion, in oncological practice, estimation of GFR at the bedside is crucial, since renal insufficiency is directly related to increased chemotherapeutic complications. It is necessary to pay close attention to decline in renal function in platinum-based chemotherapy, even in the case of carboplatin-based therapy. Patients with favorable renal condition whose pre-treatment measured- $\mathrm{CrCl}>90 \mathrm{ml} / \mathrm{min}$ may be capable of undergoing cisplatin-based chemotherapy; however, careful evaluation of renal function is essential, particularly in elderly patients.

\section{References}

1. Satoh H, Kurishima K, Nakamura R, et al: Lung cancer in patients aged 80 years and over. Lung Cancer 65: 112-118, 2009.

2. Vamvakas L, Saloustros E, Karampeazis A and Georgoulias V: Advanced non-small-cell lung cancer in the elderly. Clin Lung Cancer 10: 158-167, 2009.

3. Lang K, Marciniak MD, Faries D, et al: Trends and predictors of first-line chemotherapy use among elderly patients with advanced non-small cell lung cancer in the United States. Lung Cancer 63: 264-270, 2009
4. Sanborn RE: Cisplatin versus carboplatin in NSCLC: is there one 'best' answer? Curr Treat Options Oncol 9: 326-342, 2008.

5. Thyss A, Saudes L, Otto J, Creisson A, Gaspard MH, Dassonville O, et al: Renal tolerance of cisplatin in patients more than 80 years old. J Clin Oncol 12: 2121-2125, 1994.

6. Lababede O, Meziane M and Rice T: Seventh edition of the cancer staging manual and stage grouping of lung cancer: quick reference chart and diagrams. Chest 139: 183-189, 2011.

7. Cockcroft DW and Gault MH: Prediction of creatinine clearance from plasma creatinine. Nephron 16: 31-41, 1976.

8. Horio $\mathrm{M}$ and Orita Y: Comparison of Jaffē rate assay and enzymatic method for the measurement of creatinine clearance. Jap J Nephrol 38: 296-299, 1996.

9. Sweileh WM, Sawalha AF, Zyoud SH, Al-Jabil SW and Shraim NY: Prevalence of reduced renal function among diabetic hypertensive patients. Int J Physiol Pathophysiol Pharmacol 1: 41-47, 2009.

10. Wu MC, Lee WJ, Tschen SM, Lin SY, Lee IT, Jeng CY, et al: Predictors of mortality in hospitalized diabetic patients: A 7-year prospective study. Diabetes Res Clin Pract 80: 449-454, 2008.

11. Briguori C, Colombo A, Violante A, Balestrieri P, Manganelli F, Paolo Elia P, et al: Standard vs double dose of $\mathrm{N}$-acetylcysteine to prevent contrast agent associated nephrotoxicity. Eur Heart J 25: 206-211, 2004.

12. Quoix E: Carboplatin-based Doublet Effective for Elderly Patients with NSCLC. Plenary Session at ASCO's 2010 Annual Meeting (Abstract 2).

13. Kaplan C, Pasternack B, Shah H and Gallo G: Age-related incidence of sclerotic glomeruli in human kidneys. Am J Pathol 80: 227-234, 1975.

14. Tauchi H, Tsuboi K and Sato K: Histology and experimental pathology of senile atrophy of the kidney. Nagoya Med J 4: 71-97, 1958.

15. Levey AS: Measurement of renal function in chronic renal disease. Kidney Int 38: 167-184, 1990.

16. Beck LH: Changes in renal function with aging. Clinics in Geriatric Medicine 11: 199-209, 1998.

17. Herig PJ and Carlson RE: Plasma creatinine and renal function in the elderly. JAMA 248: 31, 1982.

18. Millward MJ, Webster LK, Toner GC, et al: Carboplatin dosing based on measurement of renal function - experience at the Peter MacCallum Cancer Institute. Aust N Z J Med 26: 372-379, 1996.

19. Peters AM: Quantification of renal haemodynamics with radionucleotides. Eur J Nucl Med 18: 274-286, 1991.

20. Fawdry RM, Gruenewald SM, Collins LT and Roberts AJ: Comparative assessment of the techniques for estimation of glomerular filtration rate with 99mTc-DTPA. Eur J Nucl Med 11: 7-12, 1985.

21. Rehling M, Møller ML, Thamdrup B, Lund JO and Trap-Jensen J: Simultaneous measurement of renal clearance and plasma clearance of $99 \mathrm{mTc}$-labelled diethylenetriaminepenta-acetate, $51 \mathrm{Cr}$-labelled ethylenediaminetetra-acetate and inulin in man. Clin Sci (Lond) 66: 613-619, 1984. 